\title{
Control of Crystallinity in Nanocrystalline Silicon Prepared by High Working Pressure Plasma-Enhanced Chemical Vapor Deposition
}

\author{
Jung-Dae Kwon, ${ }^{1}$ Kee-Seok Nam, ${ }^{1}$ Yongsoo Jeong, ${ }^{1}$ Dong-Ho Kim, ${ }^{1}$ \\ Sung-Gyu Park, ${ }^{1}$ and Si-Young Choi $^{2}$ \\ ${ }^{1}$ Surface Technology Division, Korea Institute of Materials Science, Changwon, Gyeongnam 641-831, Republic of Korea \\ ${ }^{2}$ Advanced Characterization \& Analysis Group, Korea Institute of Materials Science, Changwon, \\ Gyeongnam 641-831, Republic of Korea \\ Correspondence should be addressed to Jung-Dae Kwon, jdkwon@kims.re.kr and Si-Young Choi, youngchoi@kims.re.kr
}

Received 4 May 2012; Revised 24 July 2012; Accepted 24 July 2012

Academic Editor: Pavel Lejcek

Copyright ( 12012 Jung-Dae Kwon et al. This is an open access article distributed under the Creative Commons Attribution License, which permits unrestricted use, distribution, and reproduction in any medium, provided the original work is properly cited.

\begin{abstract}
The crystalline volume of nanocrystalline silicon ( $\mathrm{Si}$ ) films could be successfully controlled simply by changing the substrate scan speed at the high working pressure of 300 Torr. The Si crystalline volume fraction was increased from $30 \%$ to $57 \%$ by increasing the scan speed from 8 to $30 \mathrm{~mm} / \mathrm{s}$. When the Si film was prepared at a low scan speed $(8 \mathrm{~mm} / \mathrm{s})$, Si crystals of size $5 \mathrm{~nm}$ grew homogeneously through the whole film. The higher scan speed was found to accelerate crystallization, and crystals of size up to $25 \mathrm{~nm}$ were deposited in the Si film deposited when the scan speed was $30 \mathrm{~mm} / \mathrm{s}$.
\end{abstract}

\section{Introduction}

Nanocrystalline silicon ( $\mathrm{Si}$ ) films are mixed-phase materials containing a crystalline $\mathrm{Si}$ phase and an amorphous $\mathrm{Si}$ phase; they have attracted a lot of interests because of their superior properties, such as high stability against light soaking, high doping efficiency, and improved carrier mobility, compared to those of amorphous Si $[1,2]$. Control of the crystalline volume is crucial because the $\mathrm{Si}$ crystallinity has a significant influence on the optical gap and conductivity of the materials [3]. For example, in a tandem Si thin film solar cell, the best performance is achieved with a material of low crystalline volume [4]. In contrast, for the gate of a thin film transistor (TFT), nanocrystalline $\mathrm{Si}$ with a high crystalline volume and uniform grain size is required for high mobility and good stability [5, 6]. The commonest method of obtaining nanocrystalline $\mathrm{Si}$ is plasma-enhanced chemical vapor deposition (PECVD) using a mixture of silane $\left(\mathrm{SiH}_{4}\right)$ and hydrogen $\left(\mathrm{H}_{2}\right)$ gases; hydrogenated nanocrystalline $\mathrm{Si}(\mathrm{nc}-\mathrm{Si} \mathrm{H})$ is formed, and its crystallinity depends on the $\mathrm{H}_{2}$ flow rate or the plasma power
[3, 7-9]. Hydrogen radicals are known to preferentially etch amorphous $\mathrm{Si}$, and the exothermic heat generated during etching allows local recrystallization by chemical annealing $[10,11]$.

Here, we tried to develop a new method of fabricating homogeneous nc-Si:H films. We used a high working pressure plasma-enhanced chemical vapor deposition (HWPPECVD) system with a cylindrical rotary electrode; this system is superior to conventional PECVD because it has the following features: a high deposition rate as a result of the high partial pressure of the reactive gas and a high plasma density by the very high frequency of $150 \mathrm{MHz}$; the ability to control the film uniformity because of the homogeneous distribution of reactants by the rotary electrode system; low bombardment damage because of the lower kinetic energy [12-16]. We were able to synthesize nc-Si:H films using HWP-PECVD and even control the crystallinity using a simple parameter, that is, the substrate scan speed. This is in contrast to most research focusing on conventional PECVD, where the crystallinity of nc-Si:H films was controlled by the $\mathrm{SiH}_{4}: \mathrm{H}_{2}$ ratio, as mentioned above. 


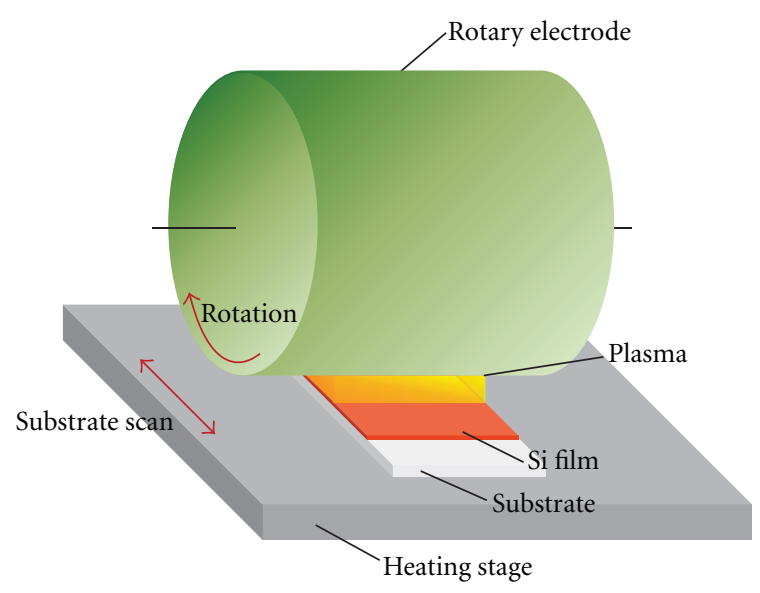

FIgURE 1: Schematic illustration of the experimental setup.

\section{Experimental}

The HWP-PECVD system used to produce nc-Si:H was based on previously reported designs (see Figure 1) [1216]. The diameter of the cylindrical rotary electrode was $200 \mathrm{~mm}$, and the width was $100 \mathrm{~mm}$. The HWP-PECVD of nc-Si:H was performed on $0.7 \mathrm{~mm}$ thick soda-lime glass $(50 \times 50 \mathrm{~mm})$ substrates at $250^{\circ} \mathrm{C}$, with a deposition pressure of 300 Torr. Before deposition, the base pressure of the chamber was reduced to $3 \times 10^{-5}$ Torr, using dry and turbo molecular pumps. After closing the main valve connected to the turbo molecular pump, helium (He), $\mathrm{H}_{2}$, and $\mathrm{SiH}_{4}$ gases were simultaneously injected into the chamber until a pressure of 300 Torr was attained, and not supplied into chamber during Si film deposition. The purity of the gases was $99.999 \%$. The $\mathrm{SiH}_{4}$ concentration was $0.05 \%$, and the ratio of the $\mathrm{H}_{2} / \mathrm{SiH}_{4}$ flow-rates was 70 . The electrode rotation speed was $1000 \mathrm{rpm}$, and the deposition gap between the electrode and the substrate was $0.5 \mathrm{~mm}$. The substrate scan distance was $50 \mathrm{~mm}$, and the scan speed was varied from 8 to $50 \mathrm{~mm} / \mathrm{s}$. All of the Si films were $500 \mathrm{~nm}$ thick by regulating the number of substrate scan depending on the scan speed. An impedance matching unit supplied $150 \mathrm{MHz}$ VHF power of $200 \mathrm{~W}$ to the electrode.

The Si film thickness on the glass was measured by $\alpha$ step (TENCOR P-11). The deposited films were identified by X-ray diffraction (XRD: X-PERT PRO, PANalytical, Almelo, The Netherlands) using $\mathrm{Cu} \mathrm{K} \alpha$ radiation with an angular domain between $20^{\circ}$ and $50^{\circ}(2 \theta)$. For confirmation of the Si crystalline volume fraction, Raman spectra were measured using a Jobin Yvon LabRam HR800 (Horibo, Ltd., Kyoto, Japan) UV/micro-Raman spectrometer at room temperature. The measurements were carried out at $514.5 \mathrm{~nm}$ using an $\mathrm{Ar}^{+}$laser, below $50 \mathrm{~mW}$ to avoid thermally induced crystallization. The microstructures of the films were observed by transmission electron microscopy (TEM: JEM-2100F, JEOL, Tokyo, Japan) at $200 \mathrm{kV}$. The TEM specimens for cross-sectional observations were prepared by using $\mathrm{Ar}$ ion source of $3.2 \mathrm{keV}$ with precision ion polishing system (PIPS).

\section{Results and Discussion}

The XRD results show that pure cubic Si was successfully deposited, regardless of the scan speed. The most significant difference among the Si film samples obtained at various scan speeds was that the $\mathrm{Si}$ (111) or (220) peaks of films produced at lower scan speeds appeared to be broader. Since the crystallinity reduces the path differences of the X-rays, the degree of crystallinity can be inferred from the full-width halfmaximum (FWHM) of the XRD peaks. The differences in the FWHMs imply that the scan speed affected the crystalline volume fraction as well as the crystalline size; the crystallinity improved at faster scan speeds. The crystallinity of the Si films was confirmed by Raman spectroscopy, as shown in Figures 2(b)-2(e). The Si transverse optical (TO) peaks were deconvoluted into their integrated crystalline Gaussian peak $\left(I_{c}, \sim 520 \mathrm{~cm}^{-1}\right)$, amorphous Gaussian peak $\left(I_{a}, \sim 480 \mathrm{~cm}^{-1}\right)$, and intermediate Gaussian peak $\left(I_{m}, \sim 510 \mathrm{~cm}^{-1}\right)[17,18]$, denoted by pink, blue, and green lines, respectively. In the case of the low substrate scan speed of $8 \mathrm{~mm} / \mathrm{s}$, shown in Figure 2(b), the integrated amorphous Gaussian peak comprised the largest proportion of the total area of the three peaks. The crystallinity in the deposited Si film was enhanced by the increase in the substrate scan speed, and thus the prevalent peak was found to be the crystalline Gaussian peak when the Si film was deposited at a scan speed of $30 \mathrm{~mm} / \mathrm{s}$. The crystalline volume fraction $\left(X_{c}\right)$ was calculated from the simple equation, $X_{\mathrm{c}}=\left(I_{c}+I_{m}\right) /\left(I_{c}+I_{m}+I_{a}\right)$, and $X_{\mathrm{c}}$ was found to increase gradually from $30 \%$ to $57 \%$ as the substrate scan speed increased from 8 to $30 \mathrm{~mm} / \mathrm{s}$. We could therefore successfully control the crystallinity of pure Si thin films by the scan speed in the HWP-PECVD method.

We performed TEM observations to investigate the detailed microstructures of the Si films. Figures 3(b) and 4(b) show the bright-field TEM (BF-TEM) images of the Si films deposited at scan speeds of $8 \mathrm{~mm} / \mathrm{s}$ and $30 \mathrm{~mm} / \mathrm{s}$, respectively. Both images indicated that the thicknesses of the Si films were all around $500 \mathrm{~nm}$ and there appeared to be no defective structures such as voids and cracks. Darkfield TEM (DF-TEM) images were also recorded, as shown in Figures 3(a) and 4(a); DF-TEM images are able to directly reveal the crystallinity of the $\mathrm{Si}$ films since the delicate contrast differences, dominant in samples, such as those in this study, comprising mixtures of embedded crystalline and amorphous phases, can be detected by reducing the beam intensity [19]. In the DF-TEM image in Figure 3(a), the crystalline phase exhibits a brighter contrast and a few nanometer-sized Si crystals seem to be homogeneously distributed through the whole Si film. To confirm the results obtained from the DF-TEM images, high-resolution TEM (HR-TEM) images, shown in Figures 3(c), 3(d), and 3(e), were taken from the top, middle, and bottom areas of the Si film. It must first be noted that the HR-TEM images were converted into colored images in which the amorphous phase is green and the crystalline phase is red/yellow. The crystalline phase areas denoted by red/yellow exhibit clear lattice images, but the green areas denoting the amorphous phases do not indicate any atomically ordered structures. Thus, as the DF-TEM image in Figure 3(a) implied, the size 


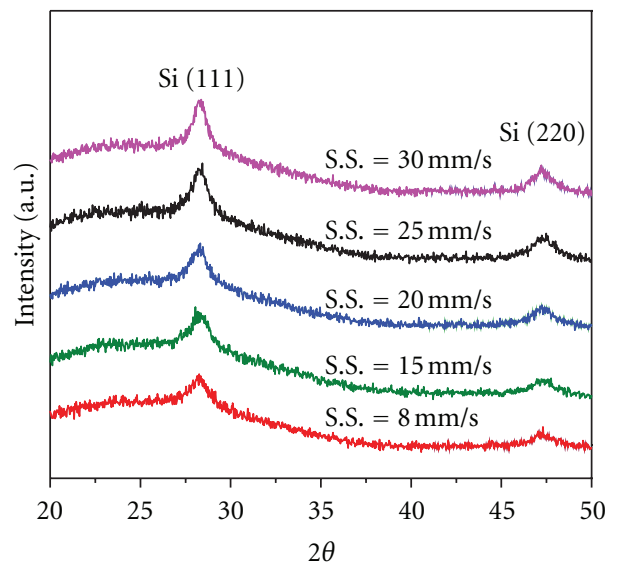

(a)

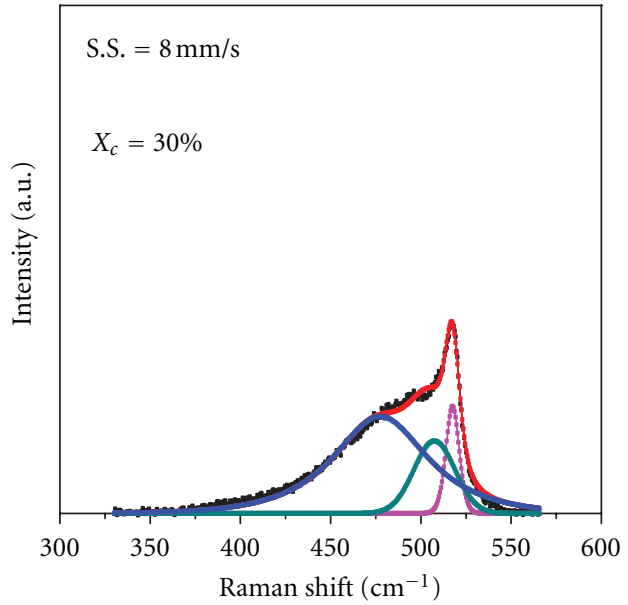

(b)

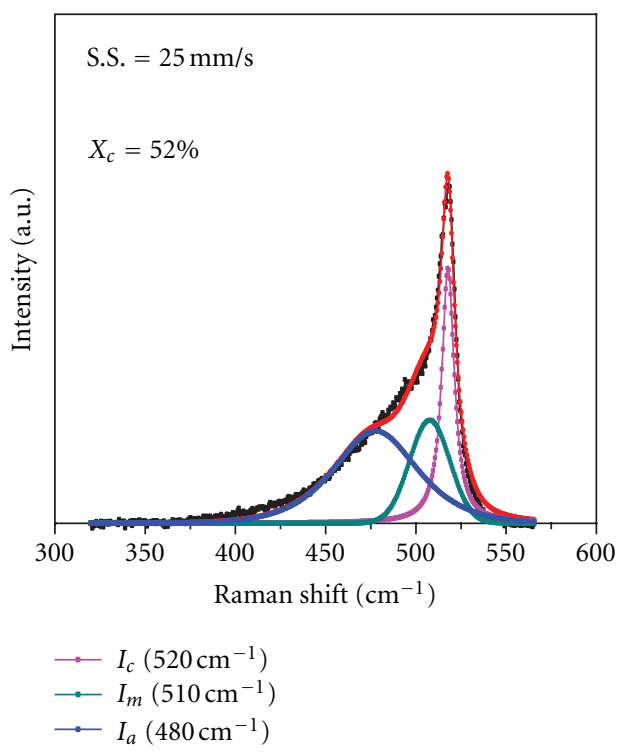

(d)

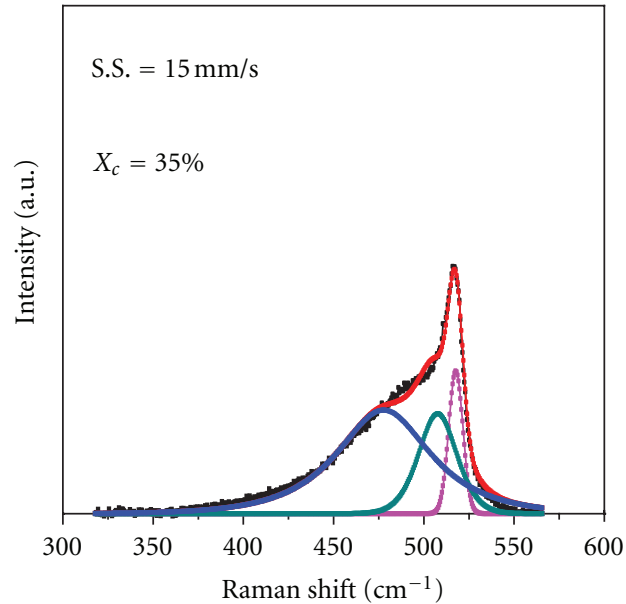

(c)

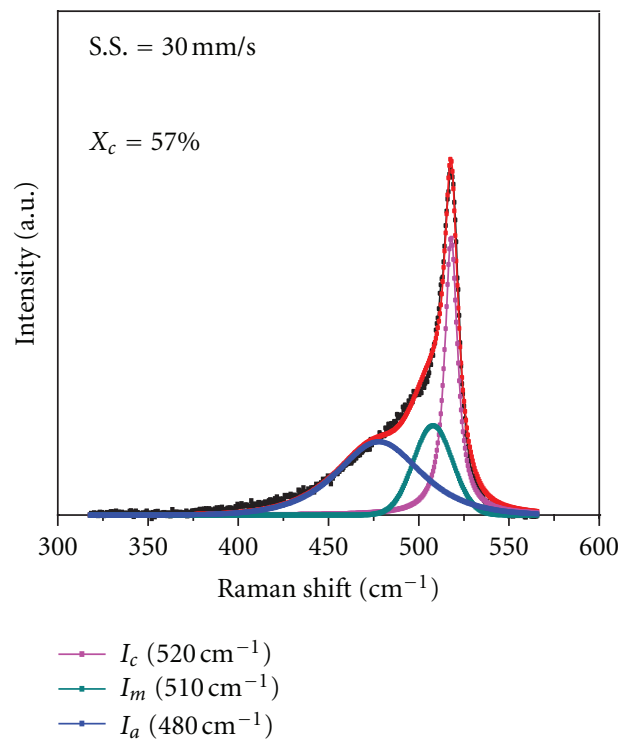

(e)

FIGURE 2: (a) XRD patterns obtained from HWP-PECVD Si films at different substrate scan speeds; the Raman spectra of Si films grown at substrate scan speeds (S.S.) (b) $8 \mathrm{~mm} / \mathrm{s}$, (c) $15 \mathrm{~mm} / \mathrm{s}$, (d) $25 \mathrm{~mm} / \mathrm{s}$, and (e) $30 \mathrm{~mm} / \mathrm{s}$. The crystalline volume fraction of the Si films increased from $30 \%$ to $57 \%$ with substrate scan speed. 

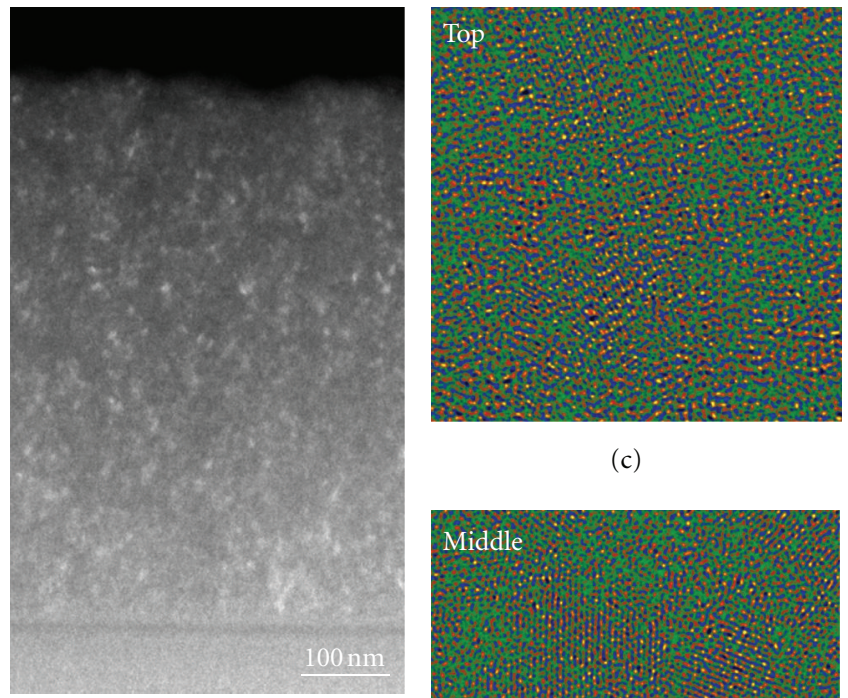

(c)

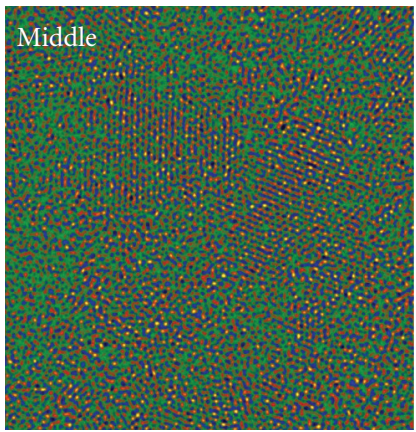

(d)

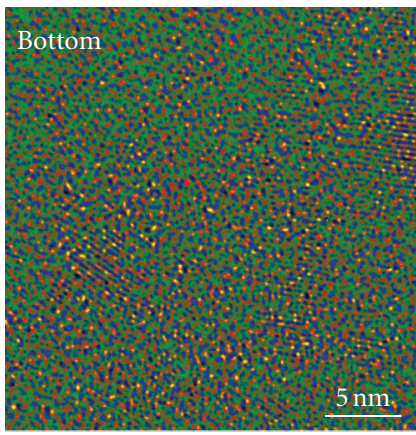

(e)

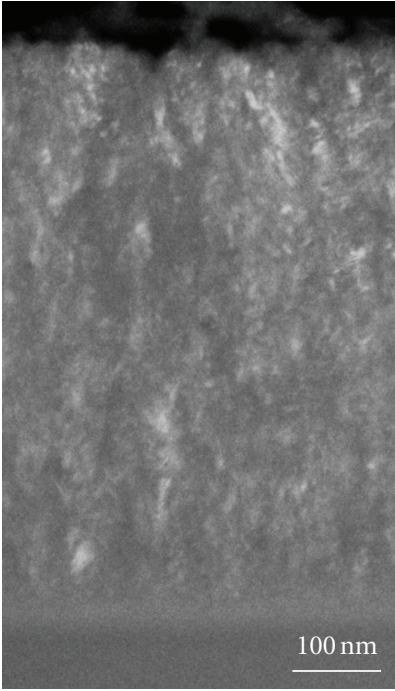

(a)

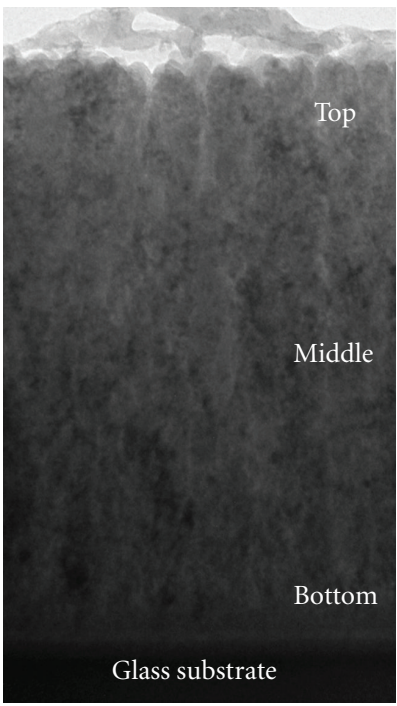

(b)

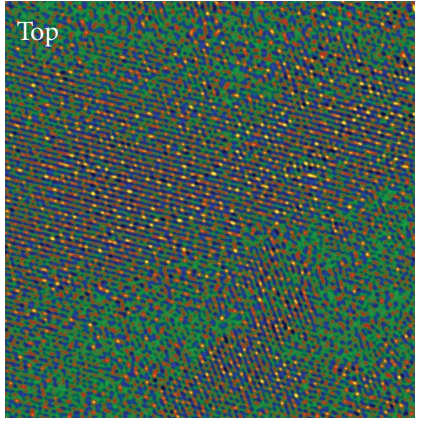

(c)

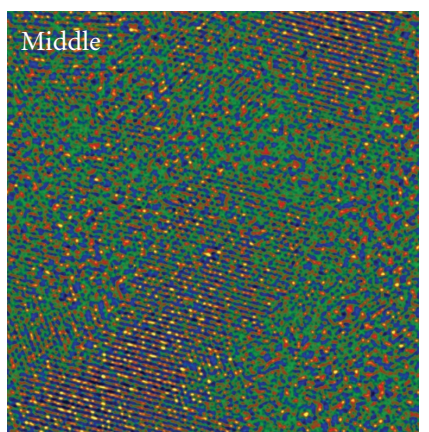

(d)

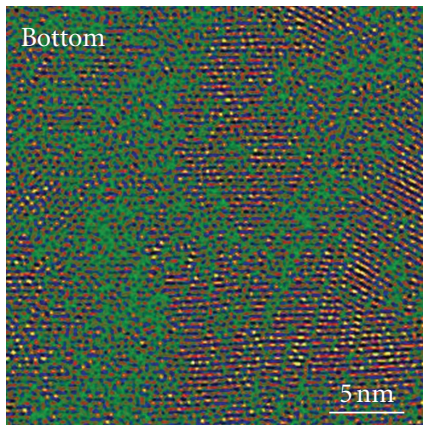

(e)

FIGURE 3: (a) Dark-field image and (b) bright-field image of Si film deposited by HWP-PECVD at a substrate scan speed of $8 \mathrm{~mm} / \mathrm{s}$. HR-TEM images (c), (d), and (e) were taken from the top, middle, and bottom areas of the Si film. The crystalline size is determined to be around $5 \mathrm{~nm}$, independent of depth direction.

of the Si crystals surrounded by the Si amorphous phase was maintained, regardless of the observed area. The crystalline size was determined to be around $5 \mathrm{~nm}$ from the HR-TEM images.

In contrast to the Si film obtained at $8 \mathrm{~mm} / \mathrm{s}$, crystallization was faster and thus the Si crystals became larger through the whole of the Si film obtained at $30 \mathrm{~mm} / \mathrm{s}$. Figure 4 shows that Si crystals of size around $25 \mathrm{~nm}$ were observed in the bottom, middle, and top layers. Our results therefore suggest that $\mathrm{Si}$ nanocrystals embedded in a $\mathrm{Si}$ amorphous phase can be fabricated by the HWP-PECVD method, and the nanocrystalline size can be controlled by simply using the substrate scan speed. This controllability of Si nanocrystalline size by substrate scan speed is found

Figure 4: (a) Dark-field image and (b) bright-field image of Si film deposited by HWP-PECVD at a substrate scan speed of $30 \mathrm{~mm} / \mathrm{s}$. HR-TEM images (c), (d), and (e) were taken from the top, middle, and bottom areas of the Si film. The crystalline size is determined to be around $25 \mathrm{~nm}$ through the whole Si film.

to be related to the effective deposition thickness, as shown in Figure 5. As the substrate scan speed was raised from 8 to $50 \mathrm{~mm} / \mathrm{s}$, the effective deposition thickness during each scan was found to decrease from 8 to $1.5 \mathrm{~nm}$. The crystalline size was increased from 5 to $25 \mathrm{~nm}$ when the substrate scan speed was increased from 8 to $30 \mathrm{~mm} / \mathrm{s}$, and further the size was slightly increased to $30 \mathrm{~nm}$ at the speed of $50 \mathrm{~mm} / \mathrm{s}$. The enhanced crystal nucleation and growth in the thinner Si film can be explained by classical crystal-growth and nucleation theory, described by

$$
r^{*}=\frac{2 \gamma \Omega}{\mathrm{kT} \ln \left(C / C_{0}\right)},
$$




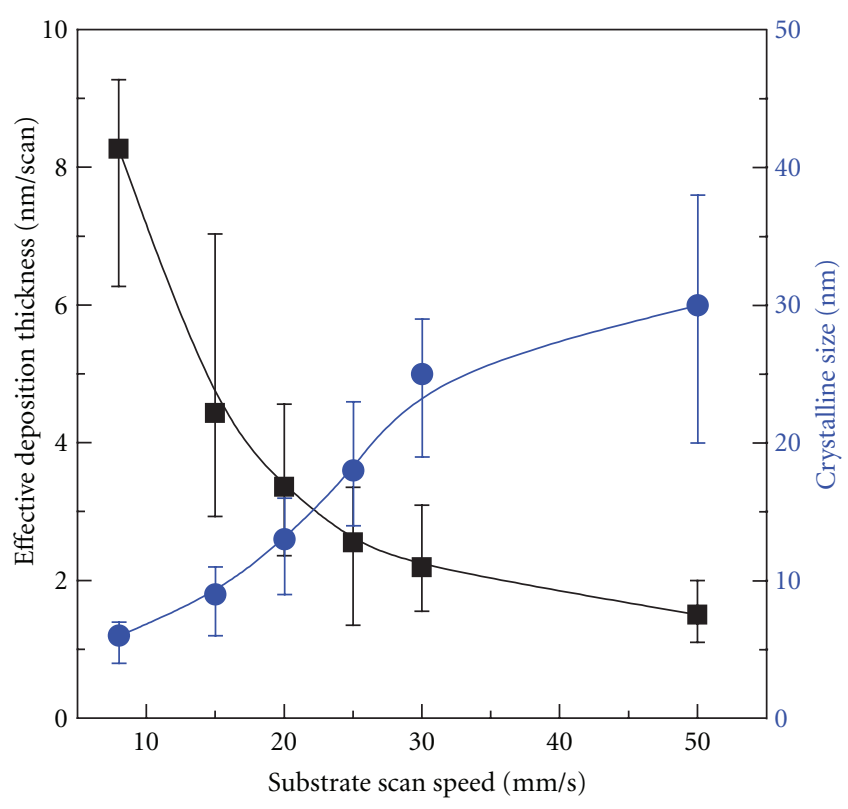

Figure 5: Dependence of the effective deposition thickness and crystalline size of HWP-PECVD Si films on substrate scan speed at a deposition temperature of $250^{\circ} \mathrm{C}$. The effective deposition thickness during each scan decreased from 8 to $1.5 \mathrm{~nm}$ with an increase of substrate scan speed; the Si crystalline size increased from 5 to $30 \mathrm{~nm}$.

where $r^{*}$ is the critical size of the crystal nucleus, $C$ is the concentration of the solute, $C_{0}$ is the equilibrium solubility, $\Omega$ is the atomic volume, and $\gamma$ is the interfacial energy per unit area. Since the interfacial energy and the deposition temperature are regarded as being invariant in our HWPPECVD, regardless of the scan speed, the only variable causing significant changes in the crystal-growth behavior is assumed to be the reactant supersaturation, expressed by $C / C_{0}$. The thinner $\mathrm{Si}$ film is exposed to more of the active radicals and ionized atoms in the plasma, which are involved in augmented reactant supersaturation. Smaller Si crystal nuclei initially form according to (1), and the Si crystal growth is then enhanced because the crystal growth can be improved by smaller crystal nuclei as well as higher reactant supersaturation $[20,21]$. Besides, as the effective deposition thickness decreased, the surface diffusion involved with crystal nucleation is thought to be more effective. The substrate scan speed is therefore regarded as being a key factor in the case of HWP-PECVD, unlike the case of conventional low-pressure PECVD techniques without a moving substrate.

\section{Conclusions}

Nanocrystalline Si films were deposited by HWP-PECVD, using a cylindrical rotary electrode. The crystalline volume fraction of Si could be controlled by changing the substrate scan speed. At a low scan speed of $8 \mathrm{~mm} / \mathrm{s}$, the $X_{c}$ was $30 \%$ and $\mathrm{Si}$ crystals of size around $5 \mathrm{~nm}$ were homogeneously distributed through the whole Si film. As the substrate scan speed was increased to $30 \mathrm{~mm} / \mathrm{s}$, the $X_{c}$ gradually increased to $57 \%$, crystal growth was accelerated, and Si crystals around $25 \mathrm{~nm}$ in size were found to form in the deposited Si film.

\section{Acknowledgment}

The present research was supported by the research fund of the Korea Institute of Materials Science, a subsidiary branch of the Korea Institute of Machinery and Materials.

\section{References}

[1] J. Meier, R. Flückiger, H. Keppner, and A. Shah, "Complete microcrystalline $\mathrm{p}-\mathrm{i}-\mathrm{n}$ solar cell—crystalline or amorphous cell behavior," Applied Physics Letters, vol. 65, no. 7, pp. 860862, 1994.

[2] B. Rech, T. Roschek, T. Repmann, J. Müller, R. Schmitz, and W. Appenzeller, "Microcrystalline silicon for large area thin film solar cells," Thin Solid Films, vol. 427, no. 1-2, pp. 157-165, 2003.

[3] Y. He, C. Yin, G. Cheng, L. Wang, X. Liu, and G. Y. Hu, "The structure and properties of nanosize crystalline silicon films," Journal of Applied Physics, vol. 75, no. 2, pp. 797-803, 1994.

[4] G. Beaucarne, "Silicon thin-film solar cells," Advances in OptoElectronics, vol. 2007, Article ID 36970, 12 pages, 2007.

[5] P. Roca i Cabarrocas, Y. Djeridane, V. D. Bui, Y. Bonnassieux, and A. Abramov, "Critical issues in plasma deposition of microcrystalline silicon for thin film transistors," Solid-State Electronics, vol. 52, no. 3, pp. 422-426, 2008.

[6] M. Oudwan, O. Moustapha, A. Abramov, D. Daineka, Y. Bonnassieux, and P. Roca i Cabarrocas, "Threshold voltage shift under electrical stress in amorphous, polymorphous, and microcrystalline silicon bottom gate thin-film transistors," Physica Status Solidi A, vol. 207, no. 5, pp. 1245-1248, 2010.

[7] A. Parashar, S. Kumar, J. Gope, C. M. S. Rauthan, S. A. Hashmi, and P. N. Dixit, "RF power density dependent phase formation in hydrogenated silicon films," Journal of NonCrystalline Solids, vol. 356, no. 35-36, pp. 1774-1778, 2010.

[8] C. H. Lee, M. Shin, M. H. Lim et al., "Material properties of microcrystalline silicon for solar cell application," Solar Energy Materials and Solar Cells, vol. 95, no. 1, pp. 207-210, 2011.

[9] Y. Q. Guo, R. Huang, J. Song, X. Wang, and Y. X. Zhang, "Nanocrystalline silicon films grown at high pressure in very high frequency plasma enhanced chemical vapor deposition system," Materials Science Forum, vol. 663-665, pp. 11711174, 2011.

[10] M. Heintze, W. Westlake, and P. V. Santos, "Surface controlled plasma deposition and etching of silicon near the chemical equilibrium," Journal of Non-Crystalline Solids, vol. 164-166, no. 2, pp. 985-988, 1993.

[11] P. Roca i Cabarrocas, N. Layadi, T. Heitz, B. Drévillon, and I. Solomon, "Substrate selectivity in the formation of microcrystalline silicon: mechanisms and technological consequences," Applied Physics Letters, vol. 66, no. 26, article 3603, 3 pages, 1995.

[12] Y. Mori, K. Yoshii, H. Kakiuchi, and K. Yasutake, "Atmospheric pressure plasma chemical vapor deposition system for highrate deposition of functional materials," Review of Scientific Instruments, vol. 71, no. 8, pp. 3173-3177, 2000.

[13] H. Kakiuchi, M. Matsumoto, Y. Ebata et al., "Characterization of intrinsic amorphous silicon layers for solar cells prepared at extremely high rates by atmospheric pressure plasma chemical 
vapor deposition," Journal of Non-Crystalline Solids, vol. 351, no. 8-9, pp. 741-747, 2005.

[14] H. Kakiuchi, Y. Nakahama, H. Ohmi, K. Yasutake, K. Yoshii, and Y. Mori, "Investigation of deposition characteristics and properties of high-rate deposited silicon nitride films prepared by atmospheric pressure plasma chemical vapor deposition," Thin Solid Films, vol. 479, no. 1-2, pp. 17-23, 2005.

[15] H. Kakiuchi, H. Ohmi, Y. Kuwahara et al., "High-rate deposition of intrinsic amorphous silicon layers for solar cells using very high frequency plasma at atmospheric pressure," Japanese Journal of Applied Physics, Part 1, vol. 45, no. 4B, pp. 35873591, 2006.

[16] H. Kakiuchi, H. Ohmi, Y. Yamaguchi, K. Nakamura, and K. Yasutake, "Low refractive index silicon oxide coatings at room temperature using atmospheric-pressure very high-frequency plasma," Thin Solid Films, vol. 519, no. 1, pp. 235-239, 2010.

[17] J. S. Lannin, Semiconductors and Semimetals, vol. 21, part B, Academic Press, New York, NY, USA, 1984.

[18] T. Kaneko, M. Wakagi, K. I. Onisawa, and T. Minemura, "Change in crystalline morphologies of polycrystalline silicon films prepared by radio-frequency plasma-enhanced chemical vapor deposition using $\mathrm{SiF}_{4}+\mathrm{H}_{2}$ gas mixture at $350^{\circ} \mathrm{C}$," Applied Physics Letters, vol. 64, no. 14, pp. 1865-1867, 1994.

[19] D. B. Williams and C. B. Carter, Transmission Electron Microscopy, Plenum Press, New York, NY, USA, 1996.

[20] R. F. Tournier, "Crystal growth nucleation and Fermi energy equalization of intrinsic spherical nuclei in glass-forming melts," Science and Technology of Advanced Materials, vol. 10, no. 1, Article ID 014607, 2009.

[21] P. Bennema, "Analysis of crystal growth models for slightly supersaturated solutions," Journal of Crystal Growth, vol. 1, no. 5, pp. 278-286, 1967. 

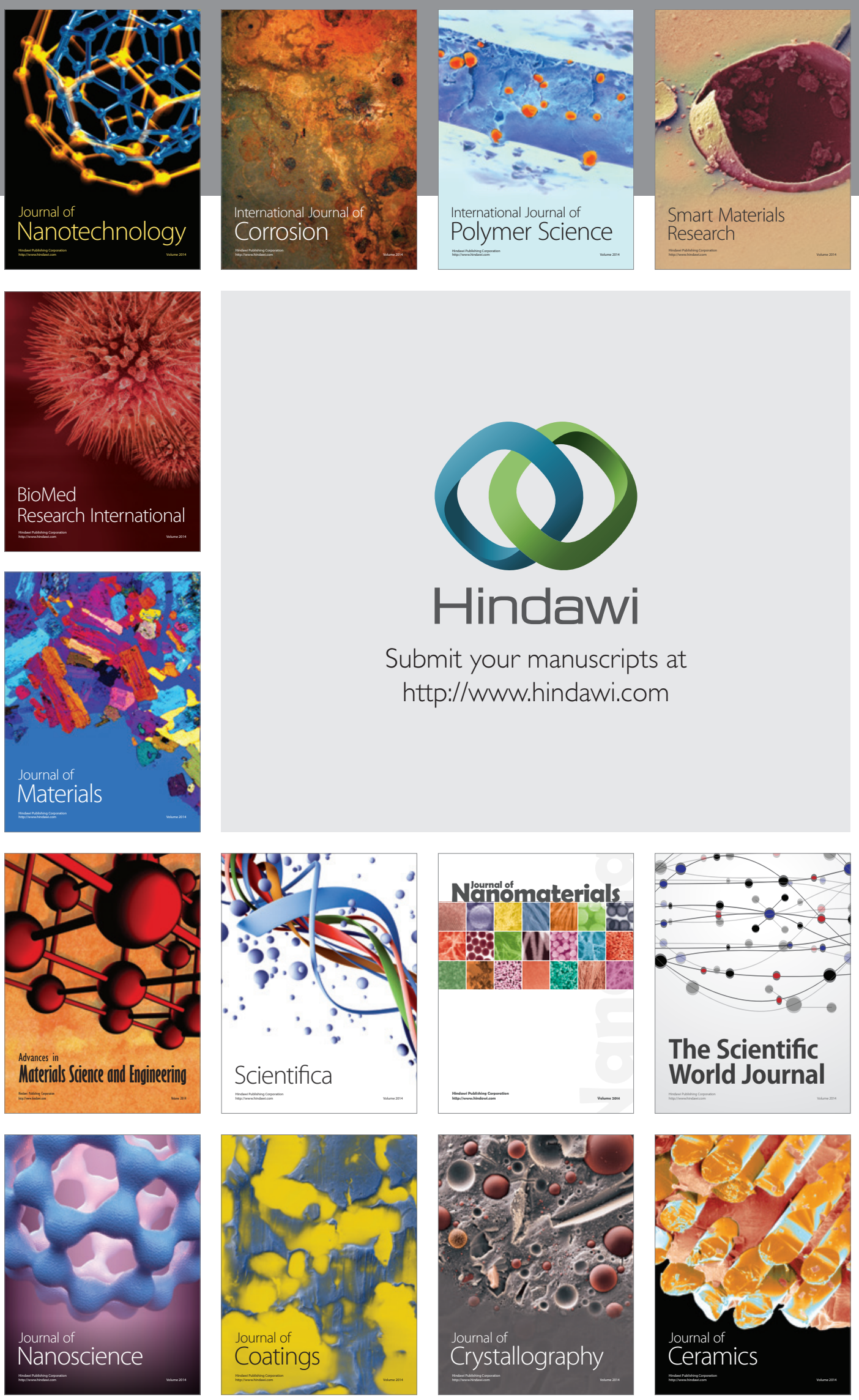

The Scientific World Journal

Submit your manuscripts at

http://www.hindawi.com

\section{World Journal}

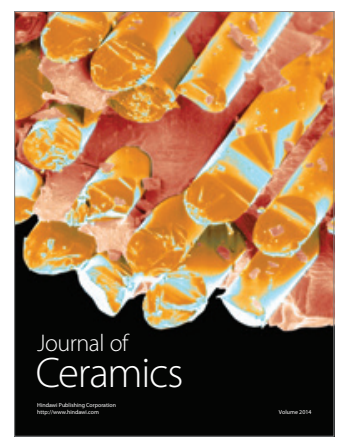

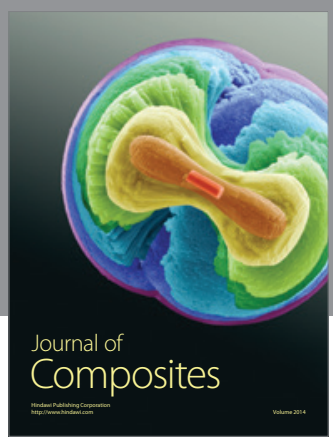
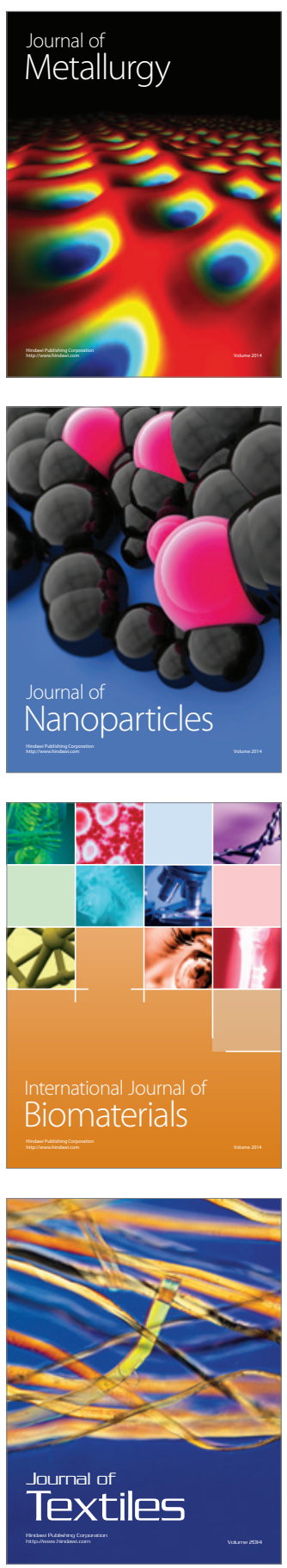